International Journal of Current Advanced Research

ISSN: O: 2319-6475, ISSN: P: 2319 - 6505, Impact Factor: SJIF: 5.995

Available Online at www.journalijcar.org

Volume 6; Issue 4; April 2017; Page No. 3353-3354

DOI: http://dx.doi.org/10.24327/ijcar.2017.3354.0270

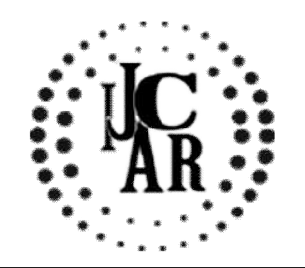

Research Article

\title{
ASSESSMENT OF THE AWARENESS OF COMPLICATIONS OF STROKE AMONG STROKE PATIENTS
}

\section{Deepti Anna John* and Halleys Kumar}

Department of General Medicine, Saveetha Dental College, Saveetha University Chennai, Tamil Nadu, India

\section{A R T I C L E I N F O}

\section{Article History:}

Received $16^{\text {th }}$ January, 2017

Received in revised form $13^{\text {th }}$ February, 2017

Accepted $22^{\text {nd }}$ March, 2017

Published online $28^{\text {th }}$ April, 2017

\section{Key words:}

Stroke, Complications, awareness

\begin{abstract}
A B S T R A C T
Aim: To assess the awareness of the complications of stroke among stroke patients.

Objective: The objective of this study is to find how many stroke patients are aware about the complications of stroke

Materials and Methods: A questionnaire will be given out to 50 stroke patients.

Background: The stroke is one of the most common cause of death and disability in India.It is an acute neurological injury that occurs due to vascular pathological injury such as brain infarction or haemorrhage.Stroke is classified into three types such as Completed stroke, Evolving stroke and Transient ischemic attack. The time at which stroke gets diagnosed determines the outcome of the disease.If left untreated for a long time, it could lead to various complications such as bed sores, deep vein thrombosis,brainoedema, pneumonia,urinary tract infections, seizures, clinical depression and also could lead to another stroke.

Reason: Due to the lack of knowledge about the complications of a stroke,could lead to further deterioration of the patient suffering from stroke.Hence awareness about the complications could help increase the mortality and morbidity of the patients.
\end{abstract}

Copyright $₫ 2017$ Deepti Anna John and Halleys Kumar. This is an open access article distributed under the Creative Commons Attribution License, which permits unrestricted use, distribution, and reproduction in any medium, provided the original work is properly cited.

\section{INTRODUCTION}

Stroke is one of the most causes of mortality and one of the leading causes for adult neurological disability.It is due to a pathologic vascular injury such as brain infarction or haemorrhage. There are three types of stroke attacks such as Completed stroke, evolving stroke and Transient ischemic attack. The main risk factors that could lead to a stroke attack are hypertension, high cholesterol, diabetes and cardiac disease[1]. Medical complications are an important issue after stroke and is a serious barrier for full recovery for the individual suffering from stroke.There a wide range of complications that occur to a patient suffering from stroke, leading to failure in rehabilitation and could also cause death.

The frequency of the complications of stroke range from $40 \%$ to $90 \%$. These complications are treatable and preventable if recognised early [2,3]. These complications are usually forgotten and lack of awareness about the complications is the reason for delayed recovery. The different types of complications that can occur are classified as Neurological, Infection, Pain, Complications of mobility, Thromboembolism and Psychological.

*Corresponding author: Deepti Anna John

Department of General Medicine, Saveetha Dental College,

Saveetha University Chennai,

Tamil Nadu, India
The aim of the study is to estimate the level of awareness of these complications among the stroke patients and to educate them about the severity of these complications.

\section{MATERIALS AND METHODS}

The study was conducted by a questionnaire survey containing 19 questions. A total of 50 stroke patients volunteered to participate in the study. Thestroke patients had been admitted for a period of 2 weeks to 3 months at the General medical ward, Saveetha Medical College, Chennai, Tamil Nadu. All the patients that participated in the study were in the recovery process. The participates consisted of both male $(n=37)$ and female $(n=13)$ patients, all belonging to an age group between $45-70$ years old.

\section{Measures}

\section{Demographic variables}

Age, Gender, Education and Residential location

Knowledge about stroke complications

The patients were asked if they were aware of the complications. They were asked about whether they experienced signs such as inability in swallowing, unexplained blackouts, weakness and numbness in the limbs, disturbances in vision and speech, infections such as Urinary tract infection, chest infection, difficulty in mobility, 
bedsores, blood clots and change in behaviour such as depression and agitation.

\section{Personal Factors}

The patients were also asked if they had a habit of smoking, drinking alcohol and tobacco chewing. History of a previous illness and previous stroke attack.

The statistics were compiled with Microsoft Excel 2016.

\section{RESULTS}

The participation rate was $100 \%$ with the sample size $(n=50)$ representatives of Saveetha Medical college, Chennai, Tamil Nadu.

Table1

\begin{tabular}{lc}
\hline & Overall sample (n=50) \\
\hline Average Age & 57.5 \\
$\quad$ Males & $74 \%$ \\
Females & $26 \%$ \\
Personal Factors: & \\
- smoker & $36 \%(18)$ \\
- previous smoker & $20 \%(10)$ \\
- heart disease & $46 \%(23)$ \\
- prior stroke & $8 \%(4)$ \\
Residential Location- Rural & $100 \%(50)$ \\
\hline
\end{tabular}

Knowledge and Experience of the stroke complications:

Table 2

\begin{tabular}{|c|c|c|}
\hline & & $\begin{array}{c}\text { Overall sample } \\
(n=50)\end{array}$ \\
\hline \multicolumn{3}{|c|}{ Neurological complications } \\
\hline - & Difficulty in swallowing & $84 \%(42)$ \\
\hline - & Inexplained blackouts & $56 \%(28)$ \\
\hline - & Weakness in the limbs & $64 \%(32)$ \\
\hline \multicolumn{2}{|r|}{ Infection } & $22 \%(11)$ \\
\hline - & Urinary tract infection & $18 \%(9)$ \\
\hline & Pain & $52 \%(26)$ \\
\hline \multicolumn{3}{|c|}{$\begin{array}{c}\text { Complications of inmobility and } \\
\text { mobility }\end{array}$} \\
\hline - & Falls & $38 \%(19)$ \\
\hline - & Bed sores & $66 \%(33)$ \\
\hline & Blood clots & $26 \%(13)$ \\
\hline & Pyschological changes & \\
\hline - & Depression & $94 \%(47)$ \\
\hline - & Agitation & $80 \%(40)$ \\
\hline
\end{tabular}

\section{DISCUSSION}

This study reports of the level of knowledge of stroke complications among stroke patients in Saveetha medical College, Chennai, Tamil Nadu. From the study it was obtained that the level of knowledge about the complications were poor but the patients were able to identify the complication based on experience. This is a major cause of concern. The findings reveal that out of all the complications, Depression-94\% was the most commonly experienced complication followed by Difficulty in swallowing (Dysphagia)- 84\%.
From other studies, it is obtained that there is a low frequency of symptomatic complications in relation to deep vein thrombosis, recurrent stroke and pulmonaryembolism. The complications regarding to pain, depression and agitation which is more difficult to spcify have shown a higher frequency in this study than others conducted.

Previous studies indicate a strong relationship between post stroke complications and poor outcome, in which the complications act as a wall for proper recovery [4]. This ensues that proper attention and care should be taken during stroke rehabilation and any signs of the complications should be treated seriously to prevent futher deterioration in the health status of the patient. Proper counselling and awareness should be given to the patients to ensure complete recovery, hence a change in the treatment plan of stroke patients should be considered.

\section{CONCLUSION}

Early recognition of the signs of the complications of stroke is the key to maximise recovery of the patient. The study evaluates the gap in the level of awareness of these complications of stroke among stroke patients. This reveals the need of proper education among the masses especially the rural community about stroke and its complications to reduce the mortality rate of stroke [5].

\section{References}

1. Hickey A, O'Hanlon. A, Mcgee H, Donnellan C,Shelley E, Horgan F.Stroke awareness among a general population:knowledge of stroke risk factors and warning signs in older adults. BMC Geriatrics 20099:35

2. LanghornP, StottD.J, RobertsonL, MacdonaldJ, JonesL.Medical complication after stroke- A Multicenter study.Stroke. 2000; 31:1223-1229.

3. Davenport RJ, Dennis MS, Wellwood I, Warlow C. Complications after acute stroke. Stroke. 1996; 27:415420.

4. Johnston KC, Li JY, Lyden PD, Hanson SK, Feasby TE, Adams R, Faught E, Haley EC, for the RANTTAS Investigators. Medical and neurological complications of ischemic stroke: experience from the RANTTAS trial. Stroke. 1999; 29:447-453.

5. Goetzel RZ, Reynolds K, Breslow L, Roper WL, Shechter D, Stapleton DC, Lapin PJ, McGinnis JM: Health promotion in later life: it's never too late. $\mathrm{Am} \mathrm{J}$ Health Promot. 2007, 21: 1-5. 10.1097/01376517200609000-00006.

\section{How to cite this article:}

Deepti Anna John and Halleys Kumar (2017) ' Assessment Of The Awareness Of Complications Of Stroke Among Stroke Patients', International Journal of Current Advanced Research, 06(04), pp. 3353-3354.

DOI: http://dx.doi.org/10.24327/ijcar.2017.3354.0270 